\title{
América Latina en tiempos de restauración neoliberal: ¿qué hacemos ahora?
}

\section{América Latina em tempos de restauração neoliberal. $\mathrm{O}$ que fazemos agora?}

\author{
Andrés Mora-Ramírez \\ Investigador \\ Instituto de Estudios Latinoamericanos \\ Universidad Nacional \\ Costa Rica \\ Recibido: 3 de junio de 2016 \\ Aceptado: 20 de agosto de 2016
}

\section{Resumen}

Este ensayo ofrece una perspectiva de interpretación de la coyuntura política latinoamericana de los últimos dos a tres años caracterizada por un lado, por lo que algunos analistas llaman fin del ciclo progresista y nacional-popular; y por el otro, por el ascenso electoral de gobiernos y partidos de derecha, que impulsan una restauración del proyecto neoliberal en la región. Se presenta una contextualización de este doble proceso y

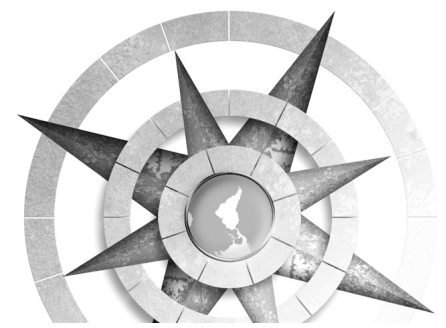

de sus principales dimensiones de conflicto, y se reflexiona, desde una posición de identificación y acompañamiento crítico con el proyecto progresista y nacional-popular latinoamericano, sobre la necesidad de que los movimientos sociales, partidos políticos e intelectuales orgánicos de las izquierdas latinoamericanas asuman como tarea la disputa por la hegemonía política y cultural frente al proyecto de actualización del neoliberalismo.

Palabras clave: coyuntura latinoamericana, gobiernos progresistas, democracia, neoliberalismo, hegemonía política y cultural. 
Hace ya más de medio siglo, el historiador estadounidense Frank Tannenbaum, un intelectual estudioso de nuestros países y sus complejas realidades, llegó a la conclusión de que el hilo conductor de la historia de América Latinaestaba atravesado por la presencia permanente de las formas de dominación autoritaria, que hacían de la democracia una excepción. "Dictadores y regímenes militares, revoluciones palaciegas y golpes de Estado, violencia y dominación violenta han sido siempre una constante política en el subcontienente americano" (Tannenbaum citado por Ansaldo, 2010: pp. 200-201) decía el autor de The future of democracy in Latin America y de Ten keys to Latin America, publicados en 1955 y 1962 respectivamente.

Esa excepcionalidad democrática fue tristemente confirmada en las últimas tres décadas del siglo XX, cuando dictaduras militares y gobiernos civiles al servicio del imperialismo estadounidense, en el contexto de la Guerra Fría, asumieron las doctrinas de seguridad nacional basadas en las tesis del enemigo interno y el peligro comunista, y pusieron en marcha las tácticas de guerra sucia y guerra de tierra arrasada, que dejaron como saldo miles de víctimas mortales y desaparecidos, y un brutal debilitamiento de las instituciones políticas. $\mathrm{Ni}$ siquiera las pretendidas transiciones democráticas, en las que muchos pueblos depositaron sus esperanzas, evitaron que las prácticas democráticas se redujeran a un ritual electoral que poca influencia tenía en el rumbo de nuestros países y en la búsqueda del bien común de nuestras sociedades.

Entrados los años noventas, la década oprobiosa del neoliberalismo y del pensamiento único, a esa democracia se le llamó de baja intensidad (O'Donnell, 1993; Ansaldi, 2010): unos pocos -élites políticas, grupos económicos transnacionales, tecnócratas y políticos recicladosdecidían por el destino de muchos. No había más alternativas que los dogmas de fe económica proclamados por el Banco Mundial y el Fondo Monetario Internacional (FMI). Y el imperio estadounidense, ahora hegemón del mundo unipolar, bendecía o rechazaba a los gobernantes de turno.

No fue sino en el ocaso de ese siglo, y a partir de una inédita articulación de resistencias de movimientos sociales, pueblos indígenas, partidos políticos y liderazgos emergentes, que América Latina se sacudió y acabó con la inercia ritualista de la democracia (neo)liberal: anquilosada e incapaz ya de responder a las demandas populares; democracia a la medida de las oligarquías, del capital extranjero y de los factores de poder de la gobernanza de la globalización. Primero en Venezuela, Brasil y Argentina, y después en Bolivia,
78 América Latina en tiempos de restauración neoliberal: ¿qué hacemos ahora? Andrés Mora-Ramírez
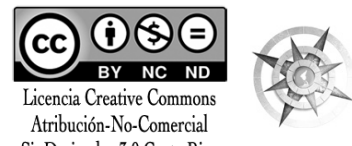
Ecuador y algunos países centroamericanos, los procesos políticos que abrieron el siglo XXI latinoamericano a la esperanza y la reconfiguración posneoliberal constituyeron, también, un avance democrático incuestionable al ampliar las dimensiones simbólicas, discursivas y materiales de las prácticas y sentidos que la democracia, tantas veces perseguida y otras tantas traicionada, había adquirido en la región.

Las luchas, avances y victorias que alcanzaron los gobiernos nacional-populares, los partidos, movimientos sociales y organizaciones populares de las más diversas y plurales expresiones, no solo permitieron derrotar sucesivamente a la derecha neoliberal en su propio terreno -el de la democracia electoral burguesa- y al imperialismo estadounidense con su emblemático proyecto panamericanista del Área de Libre Comercio de las Américas (ALCA), sino que además crearon las condiciones necesarias para articular un conjunto de iniciativas de integración regional capaces de reactivar nuestra utopía unionista, ahora en un nuevo marco de soberanía y autodeterminación, lejos de las agendas impuesta desde la Casa Blanca en Washington o desde algún despacho del FMI.

En efecto, fueron épicas las jornadas de resistencia popular y de audacia diplomática en la Cumbre de Mar del Plata en 2005, que culminaron, por un lado, con el descarrilamiento del ALCA que pretendía anexar América Latina como un mercado cautivo de las transnacionales estadounidenses; y por el otro, con la emergencia de los presidentes Néstor Kirchner, Lula da Silva y Hugo Chávez como líderes de estatura continental, capaces de poner en marcha ya no solo proyectos nacionales -basados en la recuperación del Estado, una fuerte política social, de redistribución de la riqueza y ampliación de la democracia- sino también con repercusiones en toda América Latina y el Caribe. En ese sentido, fueron memorables los encuentros que, a partir del fracaso de la aventura panamericanista, permitieron la construcción de espacios de integración como la Alternativa Bolivariana para los Pueblos de nuetra América (ALBA), la Unión de Nacionales Suramericanas (UNASUR) y la Comunidad de Estados Latinoamericanos y Caribeños (CELAC), y en un sentido mayor, la forja de un consenso nuestroamericano el cual, en buena medida, orientó la inserción de nuestra región en el nuevo mundo multipolar (Cuevas y Mora, 2015). Quizás la vieja dominación oligárquica y capitalista no fue derrotada todavía, y acaso falte mucho para que eso suceda finalmente; pero las fracturas y las heridas infligidas en los últimos tres lustros por un amplio arco de fuerzas políticas y sociales, enfrascadas en la búsqueda de

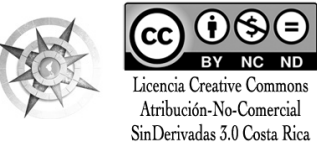


alternativas de superación del neoliberalismo, no han sido menores.

\section{Fin de ciclo progresista y restauración neoliberal: la hora de los lobos}

Sin embargo, en los últimos años el panorama político latinoamericano viene experimentando profundas transformaciones, que para muchos analistas se sintetizan en el fin del ciclo progresista o nacional-popular y el ascenso de una contraofensiva restauradora neoliberal. Especialmente importantes han sido las coyunturas políticas que se experimentan desde mediados del año 2015 y a lo largo del 2016 en Venezuela, Brasil y Argentina, países que concentran sobre sí los focos de atención política de nuestra América y el resto del mundo. Y no es para menos: si fue allí donde primero derrotaron los pueblos al neoliberalismo en el paso de entresiglos, con las sucesivas elecciones de los presidentes Hugo Chávez (1999), Lula da Silva (2002) y Néstor Kirchner (2003), respectivamente, constituyéndose en bastiones del proceso de cambio latinoamericano, ahora la confluencia de factores objetivos (crisis económica del capitalismo global, desgaste de la gestión pública, ausencia de liderazgos renovadores) y subjetivos (vaciamiento del discurso del cambio de época como horizonte de la acción política, relativo estancamiento ideológico producto de la inercia de las relaciones Estado-partidos-movimientos sociales) nos ha llevado a un punto en el que la reversión del proceso nacional-popular o progresista de la región, ha dejado de ser una hipótesis para instalarse como una realidad: sea por la vía electoral -los casos argentino y venezolano- o por la vía golpista y sus variantes jurídicas -el caso brasileño-.

En efecto, después de una década de dominio kirchnerista, Mauricio Macri recuperó el bastión neoliberal argentino -el que fue llamado el mejor alumno del modelo neoliberal de la década de 1990- en Venezuela, merced a sus tácticas de guerra económica, guerra mediática y al desgaste del gobierno de Nicolás Maduro, la llamada Mesa de la Unidad Democrática arrinconó a la Revolución Bolivariana arrebatándole el control del parlamento, después de 17 años de mayoría chavista en el poder legislativo. Y en Brasil, en la oscuridad de los pactos entre élites y mediante procesos espurios, los golpistas consumaron el proceso de impeachment para sacar de la presidencia a Dilma Rousseff.

Explicando el sentido de uno de sus más recordados filmes, Ingmar Bergman escribió que La hora del lobo (1968) es aquel momento "cuando el sueño es

80 América Latina en tiempos de restauración neoliberal: ¿qué hacemos ahora? Andrés Mora-Ramírez

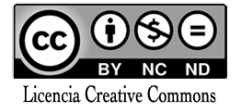


más profundo, cuando las pesadillas son más reales, cuando los insomnes se ven acosados por sus mayores temores, cuando los fantasmas y los demonios son más poderosos..." (citado por Vázquez, 2015, 13 de octubre). Como en la clásica película del cineasta sueco, América Latina está viviendo ahora su propia hora del lobo: ese paso de la esperanza posneoliberal y los sueños emancipadores, a la pesadilla de la restauración neoliberal conservadora.

El caso de Argentina resulta paradigmático de los tiempos que se anuncian: el presidente Mauricio Macri conformó un gabinete con ministros reclutados de las compañías multinacionales (los Chief Executive Officer). La CEOcracia, como ya la han denominado, se configura a partir de la designación -entre otros cargos- de las exdirectoras ejecutivas de General Motors en Aerolíneas Argentinas, de IBM y Telecom en la Cancillería; de los exdirectores de la petrolera Shell en el Ministerio de Minas y Energía, de LAN Argentina en la Jefatura de Gabinete, y del Deutsche Bank en la Secretaría de Finanzas. No menos agresivo y polémico es el nombramiento de Patricia Bulrich como responsable de la cartera de Seguridad: a Bulrich se le vincula con fundaciones de la derecha estadounidense y con la Agencia Central de Inteligencia (CIA), (Zaiat, 2015, 6 de diciembre).
En ese escenario, las derechas criollas, mediante su contraofensiva de restauración neoliberal, se han lanzado a dentelladas para constreñir el campo de resignificación de la democracia abierto a la disputa y a la construcción colectiva por los procesos nacional-populares y progresistas. El guión de esta estrategia restauradora apunta a forzar la tensión institucional, la disputa entre los poderes republicanos y la intromisión de agentes externos en sus esferas de competencia, para provocar una ruptura que justifique acciones de fuerza e intervenciones militares. El imperialismo sigue de cerca estos ensayos, y urde sus planes entre ambiguas declaraciones diplomáticas y la cooptación de partidos políticos "opositores", ministerios o secretarías de gobierno, y mandos castrenses.

Desentrañar las causas que nos han traído hasta este momento decisivo, y señalar sus posibles consecuencias, escenarios y desarrollos, es materia del mayor interés para la intelectualidad crítica latinoamericana en todos los ámbitos: gobiernos, movimientos sociales, academia, medios de comunicación.

En nuestra perspectiva, más allá de reconocer la importancia de los factores objetivos en la vida de nuestras sociedades, y la influencia que inevitablemente tienen al determinar márgenes de maniobra 
para los gobiernos que impulsan proyectos posneoliberales, el análisis debería considerar también lo que percibimos como la pérdida del rumbo del proyecto común de futuro, que parece diluirse progresivamente, en especial a partir de la muerte del presidente Chávez: su capacidad de vislumbrar un proyecto de alcance regional -bolivariano- y enunciarlo desde un posicionamiento de fuerte acento nuestroamericano, involucraba emotivamente y, al mismo tiempo, movilizaba a la acción y el compromiso de hacer realidad su concreción, no ha podido ser asumido por ninguno de los liderazgos de la región.

Ese vacío discursivo, que es también un vacío estratégico, permitió a la derecha criolla y al imperialismo recuperar posiciones en el terreno ideológico, posicionando en la esfera pública y mediática las tesis del fin de ciclo, de la crisis permanente, y en definitiva, de la inviabilidad del rumbo posneoliberal. Porque la política, qué duda cabe, es también subjetividad: búsqueda y construcción de sentidos, de relatos, de discursos que definen prácticas colectivas e individuales, formas de organización y de apropiación de lo común, de lo público. Batalla cultural, sin más. Y acaso en esta dimensión esté nuestra mayor debilidad en este momento.
En su primera visita oficial como presidente de la República Bolivariana de Venezuela a Brasil, en mayo de 1999, Chávez dio un discurso en el auditorio de la Biblioteca Central de Brasilia, y en esa ocasión, además de proponer el bolivarianismo como eje de la integración latinoamericana y de nuestra inserción en el mundo multipolar, lanzó una admonición que todavía sigue vigente: "Creo que estamos en tiempos de audacia, en tiempos de ofensiva, no en tiempos de defensiva ni de movimientos retrógrados. No, vamos adelante con nuestras banderas, con nuestro amor y con nuestros pueblos" (Chávez, 2006: p. 6).

A pesar del difícil panorama que se dibuja frente a nosotros, lo que se requiere es la voluntad y la acción consciente para seguir avanzando por los caminos de las utopías que iluminaron el nacimiento del siglo XXI latinoamericano, y el valor para enfrentar los peligros y desafíos que surgirán en esas rutas. Con el nuevo siglo, los pueblos latinoamericanos se atrevieron a andar y fueron capaces de nombrar un proyecto de común de futuro: el de nuestra América digna, soberana, justa, popular e inclusiva. No debemos olvidar esas lecciones, ni renunciar a la esperanza del otro mundo posible que solo nosotros podemos construir. Si perdemos la audacia y el amor en estos tiempos

82 América Latina en tiempos de restauración neoliberal: ¿qué hacemos ahora? Andrés Mora-Ramírez
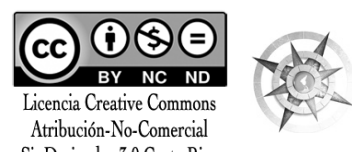
de ofensiva restauradora, como decía Chávez, lo perderemos todo.

\section{¿Qué hacer? La disputa por la hegemonía política y cultural}

Para quienes nos identificamos con el proceso de cambio latinoamericano que inauguró el siglo XXI, y asumimos una posición de acompañamiento crítico desde la academia y los medios de comunicación, es claro que nuestro futuro se encuentra ante una encrucijada: o profundizar el giro a la izquierda y la construcción de una nueva hegemonía que, con sus distintos matices característicos, más revolucionarios unos y más reformistas otros, ha permitido avances inéditos en la historia de la región, incluso a pesar de las contradicciones y errores que puedan señalarse a cada gobierno; o ceder el campo político y cultural conquistado en estos años ante la contraofensiva restauradora de la derecha regional y su propuesta de volver al pasado: a los tiempos de los ajustes estructurales y la dominación del FMI y el Banco Mundial; del desmantelamiento del Estado y las privatizaciones; del sometimiento a los dictados de la globalización neoliberal y sumisión a la política imperial de los Estados Unidos.

Por eso, no serán solo el kirchnerismo, el petismo o el chavismo los que perderán o vencerán en este episodio decisi- vo al que hemos llegado: lo que está en juego, para todas y todos nosotros, es la posibilidad de construir democracias posneoliberales, populares, nacionales, participativas y socialmente justas. Es nuestra posibilidad de ser, sin más, latinoamericanos y latinoamericanas que no renuncian a la utopía de la emancipación y la liberación. No es tiempo de señalar culpables de las derrotas o enfrascarse en discusiones estériles; como dijo Martí, "es la hora del recuento, y de la marcha unida, y hemos de andar en cuadro apretado, como la plata en las raíces de los Andes" (en Hart Dávalos, 2000: p. 203). Lo ganado hasta ahora es incuestionable; defenderlo es un imperativo ético e histórico con nuestra América y su porvenir. Y acompañar a los pueblos en esta lucha es nuestra opción.

En 1979, Pablo González Casanova publicó la primera edición de una obra que llegaría a convertirse en un clásico del pensamiento crítico latinoamericano: Imperialismo y liberación. Una introducción a la historia contemporánea de América Latina. En su libro, el intelectual mexicano sostiene que el gran protagonista de la historia de nuestra región son las masas organizadas, los pueblos en movimiento, en su persistente combate contra las diversas formas de opresión y dominación, persiguiendo el ideal de la liberación de los pueblos latinoamericanos, aún en 
medio de las más duras y adversas circunstancias que hacen de aquel un objetivo esquivo pero siempre necesario.

Ante la historia hegemónica que otorga el protagonismo a los poderosos, y de manera particular ante la expansión de sistema capitalista y del imperialismo estadounidense, que procuran conquistar América Latina sin escatimar esfuerzos y estratagemas, González Casanova (1991) revindica esa otra historia de "luchas de resistencia y liberación, en que las masas pugnan por no ser sometidas ni explotadas, o por romper los lazos que las atan" (p. 11); historia de triunfos y derrotas, de avances y retrocesos, de alianzas y traiciones, en la que "la búsqueda de la independencia es brutalmente impedida o aprovechada por las oligarquías y las burguesías" (p. 12) para imponer su dominio; y en definitiva, la historia de liberación de aquellos que entraron como "tribus, cimarrones, pueblos, plebe de las ciudades, fraternidades de artesanos, partidos, sindicatos, ligas campesinas, asociaciones estudiantiles, asociaciones de inquilinos o usuarios, órganos de poder popular, montoneras y guerrillas, con líderes, héroes e intelectuales, de letras armadas y desarmadas" (p.14).

Han pasado los años, pero vistas las actuales circunstancias a las que nos enfrentamos, así como las amenazas y desafíos enormes que nos emplazan en la conflictiva relación con los Estados Unidos, aquella interpretación general del devenir de nuestra América que propusiera González Casanova acaso está más vigente que nunca. La tensión entre imperialismo y liberación una vez más pone en jaque a la democracia que, quizás todavía precaria y frágil, ha venido siendo labrada en nuestros países tras el final de las dictaduras militares del último cuarto del siglo XX. La lucha por la construcción de sociedades más democráticas, más justas, más inclusivas, sigue siendo la gran tarea de los pueblos de nuestra América. Una lucha larga, irrenunciable, por la que, como decía la Segunda Declaración de La Habana (1962), "ya han muerto más de una vez" los pobres, los explotados, los vilipendiados.

Entonces, ¿qué hacemos ahora?

En primer lugar, es preciso reconocer que asistimos al final de una época brillante -la de la generación del Bicentenarioy seguramente polémica, pero también marcada por conquistas inéditas en las últimas décadas: en materia de derechos humanos, participación democrática y nuevo constitucionalismo, políticas sociales, lucha contra la desigualdad y la pobreza, integración regional, por citar solo algunos aspectos. Conviene que lo reconozcamos así, como un capítulo que se cierra, para empezar
84 América Latina en tiempos de restauración neoliberal: ¿qué hacemos ahora? Andrés Mora-Ramírez
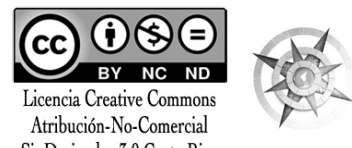
a trabajar en la reconstrucción del camino emancipador y en las nuevas resistencias con las que será necesario plantar cara a la andanada neoliberal.

Asimismo, debemos considerar que frente a los vientos de tormenta que soplan sobre la coyuntura política latinoamericana de los últimos dos años, ciertamente adversos para los gobiernos nacional-populares y progresistas, el desánimo, el desencanto y el escepticismo vuelven a presentarse como una fuerte tentación para los ciudadanos, las organizaciones sociales, los partidos y no pocos intelectuales. Los medios de comunicación y los think tank del establishment hacen su parte del trabajo construyendo una narrativa del fracaso de la izquierda y de la inviabilidad de los cambios y transformaciones que intenten siquiera cuestionar al capitalismo. Así, el sentido común neoliberal se instala nuevamente como regulación social, económica, política y cultural, y lentamente intentan hacernos creer -como en la década de los años noventas- que no hay otro horizonte más que el del reino de la libertad del dinero, los derechos de las mercancías, la esclavitud de las personas y la desigualdad inexorable.

Pero, ¿es que acaso estos quince años de victorias sobre la derecha, de experiencias revolucionarias inéditas -con sus aciertos y errores- y de búsqueda de alternativas de desarrollo no significaron nada? ¿Las conquistas de esta década y media podrán ser borradas sin más de la memoria colectiva y de la historia de las luchas populares?

No debiéramos olvidar que el camino que nos trajo hasta el cambio de época de inicios del siglo XXI no fue sencillo. Los pueblos latinoamericanos cargaban sobre su espalda los fardos de una modernización inconclusa (Domingues, 2009) y de modelos de desarrollo -impulsados desde la segunda mitad del siglo XX-cuya promesa de bienestar y prosperidad resultó fallida en más de una ocasión: unas veces traicionada por sus propios impulsores, y otras tantas boicoteada por las grandes potencias, más interesadas en preservar las condiciones neocoloniales sobre las que se asienta su dominio histórico, que por la independencia y la autonomía de nuestra América. Bárbaros y subdesarrollados (Zea, 1992), nos maldijeron, y con esa suerte fuimos tejiendo la trama de nuestro desarrollo combinado, desigual y contradictorio, como bien lo han caracterizado intelectuales como el brasileño José Mauricio Domingues (2009) o el británico David Harvey (2005 y 2014).

Condenados como estábamos, nos atrevimos a pensar por nosotros mismos, y en las décadas de 1960 y 1970 fuimos capaces de construir en América Latina un rico pensamiento social, filosófico, 
político y económico, cuyos aportes le permitieron a varias generaciones disputar la hegemonía cultural al capitalismo y las nociones dominante del desarrollo. La teoría de la dependencia, la teología y la filosofía de la liberación, y la pedagogía del oprimido, por citar algunos ejemplos, fueron banderas de lucha en el frente de las ideas, cuando en otros campos guerrillas y organizaciones populares combatían contra dictaduras y aparatos militares apoyados por el imperialismo estadounidense.

De aquella guerra total, que tuvo como desenlace la imposición del neoliberalismo y el terrorismo de Estado en prácticamente todo el continente, y con las heridas abiertas de sus oprobiosas consecuencias sociales -del Caracazo a la Guerra del Agua en Bolivia y del levantamiento zapatista de 1994 a la crisis argentina del 2001-, América Latina supo resistir, reconstituirse y pasar a la ofensiva. De la derrota militar a las sucesivas victorias electorales y de la fragmentación de la desesperanza a las grandes movilizaciones sociales, el siglo XXI rápidamente se perfiló como un tiempo de disputa hegemónica, de complejos y diversos ensayos posneoliberales, que permitieron repensar y discutir los dogmas y supuestos del neoliberalismo, y en no pocos casos, se logró avanzar sustancialmente en aspectos claves: la democracia representativa y delegativa empieza a dar paso a la democracia directa y participativa; los procesos constituyentes en varios países rompieron las aldabas del poder oligárquico y nuevos diseños constitucionales, surgidos de la deliberación colectiva, intentan dar respuestas a los desafíos económicos, políticos, sociales, ambientales y culturales; y las ideas de la unidad y la integración latinoamericana profunda remozaron unos procesos que tendían a ser cada vez más funcionales a los intereses del capital y de los Estados Unidos (Cuevas y Mora, 2015).

Hoy más que nunca resulta necesario plantar cara a la ofensiva ideológica de la derecha y asumir puestos en la batalla de las ideas, para defender no a un gobierno o a un presidente en particular, sino el derecho a ser nosotros mismos, a pensar y decidir por nuestra cuenta los rumbos que queremos seguir en América Latina. La disputa hegemónica contra el neoliberalismo, entonces, está lejos de finalizar y no se puede permitir que el relato recargado del fin de la historia termine por imponerse como la vOz unívoca que interprete y dé sentido a este tiempo nuestroamericano, sufrido pero también asombroso, que hemos vivido. Y que queremos seguir viviendo.
86 América Latina en tiempos de restauración neoliberal: ¿qué hacemos ahora? Andrés Mora-Ramírez
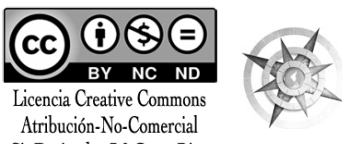


\section{Referencias bibliográficas}

Ansaldi, W. (2010). No es que la democracia esté perdida: está bien guardada y mal buscada. Revista Crítica y Emancipación, 2(3). Pp. 189-218.

Castro, F. (1962). Segunda Declaración de La Habana. Discurso pronunciado en la segunda Asamblea Nacional del Pueblo de Cuba, celebrada en la plaza de la revolucion, el 4 de febrero de 1962. Recuperado de: http:// www.cuba.cu/gobierno/discursos/1962/esp/f040262e. html

Chávez, H. (2006). La unidad latinoamericana. (Sergio Rinaldi, Ed.). Bogotá: Ocean Sur. P. 6.

Cuevas, R. y Mora, A. (2015). Buscando el futuro. Crisis civilizatoria y posneoliberalismo en América Latina. San José: EUNED.

Domingues, J. (2009). La modernidad contemporánea en América Latina. Buenos Aires: Siglo XXI Editores.

González Casanova, P. (1991). Imperialismo y liberación. Una introducción a la historia contemporánea de América Latina. México: Siglo XXI Editores.

Harvey, D. (2005). Espacios de esperanza. Madrid: Ediciones AKAL.
(2014). 17 contradicciones y el fin del capitalismo. Quito: Editorial IAEN.

Martí, J. (1891). Nuestra América, en: Hart Dávalos, A. (editor) (2000). José Martí y el equilibrio del mundo. México: Fondo de Cultura Económica, pp. 202-212.

O'Donnell, G. (1993). Estado, democratización y ciudadanía. Nueva Sociedad, (128), pp. 62-87.

Vázquez, P. (2015, 13 de octubre). Liv \& Ingmar. Escenas de la vida amorosa. Página/12. Recuperado de: http://www.pagina12. com.ar/diario/suplementos/ radar/9-10974-2015-10-13.html

Zaiat, A. (2015, 6 de diciembre). La CEOcracia. Página/12. Recuperado de: http://www.pagina12.com.ar/diario/econo$\mathrm{mia} / 2-287680-2015-12-06 . \mathrm{html}$

Zea, L. (1992). Discurso desde la marginación y la barbarie. México DF: Fondo de Cultura Económica. Pp. 23-54. 